\title{
Rethinking the Language Use within a Country to Trace the Evidence of LinguisticUniversality
}

\author{
A. M. Sudirman \\ FKIP-Universitas Muhammadiyah Metro \\ W. Ninsiana \\ IAIN Jurai Siwo Metro, Lampung, Indonesia
}

\begin{abstract}
Language phenomena and dialects (in a country) may have not been studied and described comprehensively to provide adequate answers. The method used in this study is descriptive research method with data collection techniques obtained from various sources, all research techniques that complement each other. Data were collected and analyzed and followed by data selection, compilation / classification and summary, these were conducted in an integrated manner. The method used in this study is descriptive research methodology with data collection techniques obtained from various sources that are in complement to each other. The data were collected and analyzed and followed by data selection process, compiled / classified and summarized in an integrated manner. Based on the description of the language ecology as common happens in a country wherein there is at least a foreign language (FL), the national language (NL), and the local language (LL)'; In a country there maybe possible occurs two or more bilingual communication. In the language contact we usually know the status of isolects they use. The status of a person's isolects could be as FL, NL, and LL. In other words, the isolated form of a language is a complement of the language they speak. Thus, the status of isolates in a language or a dialect used in formal situations can be demonstrated in the user's situation and its use properly and correctly as a reflection of a language use.
\end{abstract}

Keywords: Language; ecology of language; isolect; dialect; prestige of language

\section{INTRODUCTION}

Linguists are not just scholars who concentrate on the study and use of a language. In another field of study, understanding of language is a very important issue. In the study of languages, educators, philosophers, anthropologists, and students who study literature, all have an interest in mastering the language in their respective fields of expertise. Primary school teachers, who have a duty to help their students learn in reading and writing, can respond effectively only if they understand the relationship between writing and speech, at the acquisition level of the language's 'acquisition' the ability to be able to speak at school, and different language dialect roles may play a role in reading toward difficulties. Secondly, schoolteachers also need a language understanding to analyze the literary styles, as well as for the problem of the effectiveness of using grammatical composition in the learning English classes. In foreign language teaching, it is not enough to provide students with examples of the foreign language. Teachers must be aware of the rules and form that make up the language system, as FL, NL, and LL as and if students are even to achieve complete command of the foreign language, the teacher must understand the kind of linguistic knowledge possessed by a native speakers of that language (Falk, Julia S., 1978: 4).

The use of language in a sequence communicative situations to one another, expressing the personal's reaction to a situation, stimulating one's response to one another as well, and also 
exchanging thoughts. Language may be described as a means of conveying something by users who want to convey something. In this field the thought of the language of the world is used as a way of opening understanding is used to convey emotions and thoughts, from sign language to one of extreme simplifications to the language of mathematics on other extreme properties. Language is considered an instrument that we are here concentration. Efficient instruments against achievements used that cannot be achieved, for designated instruments can be achieved (Robert L. Montgomery Cs. 1962: 15).

And then, why do we use language, our daily recognition that speaks and writes there can be errors that can be recognized the complexity of our learned abilities. This is prioritized whenever we try to define the functional distance to the language used. This must be ensured that the most widely known (concerning) language functions, such as when we tell someone about ourselves or the use of language in the exchange of sequences and opinions. The use of language is often called referential, propositional or ideational. This is the kind of language that will be found in encyclopedias and in some conversational or written interactions, when people want to learn from one another. But it would be a mistake to think of it as just a way in which the language we use. Scholarly languages have identified several other functions, in which they communicate so irrelevant marginal ideas considered in effective communication (David Crystal, 1992: 10).

The effectiveness of the use of language in a communication is normally motivated by a theme (of talk). The characteristics of the learning theme, for example (a) present multi learning concepts with a more vague and unacceptable view; (B) be flexible; (C) can be developed based on students' emphasis and needs; (D) develop student experience; And (e) student-centered. As an illustration follow the possibility of visual observation as follows.

Note:

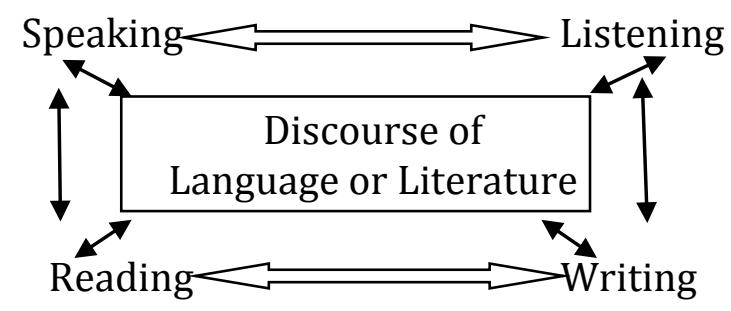

$$
\begin{aligned}
& \text { Indirect-Link }=\longleftrightarrow \\
& \text { Direct }- \text { Link }=\longleftrightarrow
\end{aligned}
$$

Given the concept of student-centered learning, these own potential characteristics through learning of language and literature as learning based on discourse themes can shape their own individual characteristics, dominated in speech, listening, reading and writing skills; through language and literature (Sudirman AM., 2016: 478)

Language problem in a country interesting to observe carefully today, one country and the other one not the same the use account of language and culture include the characteristic of language and culture too. The language use patterns are one of the important indicators of a language's vitality and the likelihood of that language continuing to be spoken in the future. A study of language use patterns attempts to describe which languages or speech varieties members of a community use in different social situation referred to as domains. The study area of social context is determined by who speaks, when and to whom "(Fasold 1984: 183) .This case has been extensively discussed in articles on the use of language in a country, that there are the distinguishing characteristics viewing a language as belong to the international, national, and even a language of prestige. Regional as a prism for speakers Today there are at 
least three aspects that we should know about the use of language, namely FL, NL, and LL within a country Foreign language is used externally between nations, the national language of others Nation and local languages are used within the internal state of a country How far is the use of those languages in a country? Which dominates the functions of the language as a medium of communication in society? Language as a phenomenon of society, the special characteristics in addition to being a symbols and arbitrary are the habits of speakers in daily activities which nobody could deny the existence. The problem of communication network found the problem lays on the language function. In addition to natural language, language as a system may be a way out for language functions as FL, NL, and LL that enable the speakers or writers to establish such system itself. In this manuscript that question is going to be answered, how far the use of language can be increased at the language level of the native speakers in a country?.

This problem in predicted expected due to the undergoing process of progress of the people's constructions which refer to the modern state, including the development of society culture and languages. "The modernization of language (of any language) will be part of the modernization process that particular society. In order words, it would be desirable that processes, the modernization of language as well as the modernization of society were synchronized" (Heidet, Karl M., 1968:28).

In this study, we try to formulate questions and answers on the statuses of isolects (the term isolect is a neutral term, that determines whether a language, dialect, sub-dialect based on a country's language). In this paper used symbols FL, NL and LL in a country. The researcher will know, in addition to comparing the facts of 'evidence' about isolects status, which is more popular and dominantly used within the community prestige network? Although far before it was asked, "How many languages or dialects exist in a country?" As Einar Haugen (1966: 922) notes earlier, that many facts, perhaps most of the languages and dialects have not been comprehensively studied and described.

\section{METHODS}

Research method of this study is under the paradigm of descriptive-qualitative methodology, problem arises in descriptive study ranging from classification of the phenomenon which is elaborated by the writer as research instrument in accordance with certain criteria that fit the research problems (Verendbregt, Jacob, 1985: 52). Technique collecting data obtained from sources in which the author carefully records and accurately manifests the words, sentences, discourses, pictures or photographs, diaries, memoranda, videotapes. From the descriptive data that researchers do data analysis to make generalizations or general conclusions which is a system or patterns that are set or images of the people who made the subject of research. (Edi Subroto, 1992: 35). The types of data collection techniques in this study, literature review, selected literary sources are reflected by the integrated use. All written material is compiled from all sources such as magazines, newspapers, literature, general books, science books, law books, and language data derived from limited literary sources based on emphasis on the topic of content and research purposes (Edi Subroto, 1992: 42-43). After the researchers conducted data collection oriented with data collection, in the next phase followed by data analysis. Data analysis (1) data filtering, (2) data compilation, (3) data conclusion, (4) data integration, all indicated by the conclusion of the research (Tarigan, 2009: 196). 


\section{DISCUSSIONS AND RESULTS OF THE STUDY}

Based on the research observe the using of language one country and the other country minimalist there are three categories in using, they are FL, NL and LL. FL used between country for example, English to Prance, Germany, Dutch, etc. The NL used in the country, precisely used between state or provinces that have a language of their respective region, i.e. in Malaysia there are state of Commonwealth, in Indonesia there are provincial government within the unions of the Indonesian inhabitants. Each state or province there are LL in addition enriching NL or FL vice versa, also used in the area itself.

All isolects is located on the ecology of languages that interact inter-isolects in one languages environment, therefore, through such ecology of languages, enable the linguistis to characteristically distinguish the international or Foreign Languages as the FL, the NL, and the LL. All of it had the characteristics of each use languages and culture in society one and the other one. This includes the development of society culture, languages, literature, and art. This opinion is supported by Einar Haugen 1972 that linguists' spirit of getting phonology, grammar and lexicon are less noticeable in the language of ecology, ecological language in a lot of benefits because of the language explored last few years outside the field of linguistics, the usefulness of the ecological aspects of language competence in the language. Ecology language can be defined as the study of the interaction between a specific language and the environment (Haugen, 1972).

In this study described the ecology of language, language contact, status isolects, isolects language, dialects isolects and element of loan and absorbed use of language in a country. In asuch implication, it is also described the function use of each isolect, weather the status of the international language or FL, NL, and LL as the mirror of usage the language base on situation user and usage in situation formal, informal, or non formal as use as prestige of language. Furthermore, its include example of elements that exflicatiand loans as a result of language contacts has occurred in the use of language. The an element uptake and loan in use of language as follow

Loan of Language

\begin{tabular}{|c|c|c|c|c|c|}
\hline \multirow[b]{2}{*}{ No. } & \multicolumn{5}{|c|}{ the Result of Loan Language in Contact } \\
\hline & FL* & NL** & LL & Etimology & Note \\
\hline 1. & $\begin{array}{l}\text { maria, david, } \\
\text { abraham }\end{array}$ & - & - & $\begin{array}{c}\text { maryam, daud, } \\
\text { ibrahim }\end{array}$ & Arabic \\
\hline 2. & book & Kitab & - & kitabun & Arabic \\
\hline 3. & soursop & Sirsak & sirsak & Portugis & Indonesian \\
\hline 4. & workshop & bengkel & bengkel & Dutch & Indonesian \\
\hline 5. & Ex- & mantan & mantan & Palembang & Indonesian \\
\hline 6. & gap & senjang & senjang & Minangkabau & Indonesian \\
\hline 7. & turf & gambut & gambut & Sunda & Indonesian \\
\hline
\end{tabular}

Note: *English as a Foreign Language; **Indonesian as a National Language

This is as maintained by Edwards (1995: 89) that as language communities come in a multilingual world, there would be need for arising for bilingualism, translation and the use of lingua franca. Proximity, necessity and convenience also lead to borrowing and interpenetration among languages.

Thus, in a common language isolects ecological status of languages or dialects in used the formal situation it is deemed good and correct. The effectiveness of the use of the language 
according to the speaker's situation and the use of the prestige the mirror use of language is good and right in a country.

\section{THE DISCUSSIONS OF LANGUAGE}

The Ecology of Language: based on the ecology of language, language ecology may be defined as the study of interaction between any given language and its environment. The true environment of a language is the society that uses it as one of their codes. Language exists only in the minds of its users and it only function in relating this user to one another and to nature. Psychological: interaction with other languages in the mind of bilingual or multilingual speaker. And then, the ecology of language is determined by the people who learned use and transmit them to others people. As common as the life of language caused the biological model came easily to a generation that had newly discovered evolution. Language were born and died, like living of organism. "They had their life spans, grew and changed look like men and animals. They had their little ill which could be cured by appropriate remedies prescribe by good grammarians" (Einar Haugen, 1972: 57-58), in the contact of language.

The Language Contacts: as common as in a country minimalism are there a foreign language (FL), nationality of language (NL), and local of language (LL). They are (FL, NL, and LL) in example in Indonesian they life spans, grew and change in one unity of geographies namely Nusantara or West of Austronesia language. One speaker and the other one happen mutually intelligible in situation society, socially or culture look like interaction formal, informal, and non formal. All of languages, they are FL, NL, and LL there a contact language. "When languages are viewed as a system or codes, it becomes of primary interest to investigate what happens when linguistics systems come into contact with each other" (Hans Vogt, 2016: 368). In the present study, two or more languages will be said to be in contact, if they are used alternatively by the same persons. The language using individuals are thus locus of the contact ... for the purposes of the present study, it is immaterial whether the two system language, dialect of the same language, or varieties of the same dialect. The greater the difference between the system, i.e. the numerous the mutually exclusive form and pattern in each, the greater is the learning problem and the potential are difference (Uriel Weinreich, 1979: 1). On the language contact we would to know the isolect, how the status of them.

The Status of Isolects: the issue the status of isolects language in a country that is involved in network language problems, has been described by Amran Halim (1979) took the example in Indonesia is a network woven by (1) issue national language, (2) the problem local languages, and (3) problem use and utilization of certain foreign languages. Processing language is necessary policy planning, effective, and comprehensive or completed. Based on social solidarity distance, one the most important functions of language variation is to enable individual s to identify with a social group or to separate themselves from it. The market of solidarity and distance may relate to family sex, ethnicity, social class or to any of the groups and institution that define the structure of society. "They may involve tiny section of the population, such as scout groups and street gangs, or complete cross-section, such as religious bodies and political parties, '[.....] the signals can be as small as single word, phrase, or pronunciation or as large as a whole language ..." (Crystal, 1992: 42).

As a described above, by sign FL, NL, and LL, in sociolinguistic all of isolect in a country the same their status, but for more clearly in this article how to know isolect from the standpoint of qualitative and quantitatively. 
If we study by qualitative method dialect and language, we use the description as suggested by Petyt as follows: "Many people hold the essential criterion to that of mutually intelligibility: dialects are different but mutually intelligible forms of speech. So if two speakers, in spite of some observable differences in their speech, can understand each other, they are held to be using different dialects; if two speakers cannot understand each other, they are speaking different languages. This seems at first sight to accord with what we intuitively feel to be the distinction between dialect and language: ... "(Petyt, K.M., 1980: 13)

And then if we want to study from the study of quantitative methods on the status of isoleh used there are several variations of isolect as follows ... to determine whether the status of isolects used (in terms of what) researchers can use the dialectometric formula as follows.

$(\mathrm{S} \times 100)$

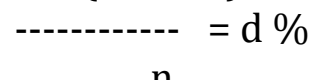

$\mathrm{n}$

The relationship one point to another in the field or area of research based on 200 lexicon Swadesh and the above dialectometric formula to know 81\% - to the top difference of language; $51 \%$ - $80 \%$ difference of dialect; $31 \%$ - $50 \%$ difference of sub dialect; $21 \%$ - 30\% difference of speech; below 20\% of no difference (Mahsun, 1995: 118). Having described the formula, then the status of the isolects can be determined whether as a dialect or language.

The Isolect of Language: a human language system is expressed with the meaning of words, the system of certain words, such as those used by people of a nation, there are several marker systems, movements, and so on, used expressions of meaning or feeling, Procter, Ed 1982: 617). As has been characterized in qualitative dialectological studies, if two speakers cannot understand each other, they are in a speech of language differences. And then quantitatively we can know, that the criteria indicating that $81 \%$ - above in which a language could be different, the subordination of language has been indicated by dialect variations.

The Isolect of Dialect: A dialect of the language is used by some inhabitants of the country or by the social class of persons characterized by the use of grammar, vocabulary and pronunciation which can be distinguished in one form by another in the same language (Hornby, USA, 1995. 319). And then by John Edwards (2011: 108) referred that case as the most common habits given a bit of each language relation becomes most evident in language planning and language ecology. Being leafy dialectological when there are two speakers, although observable in their speech, posibly understand each other, they are assumed using the same dialect. In addition to quantitatively view this phenomenon, if the dialectometric position calculation is between $51 \%$ - $80 \%$ then the dialect is different; $31 \%$ - 50\% sub-dialec difference; $21 \%$ - 30\% difference in speech; under the span of $20 \%$ there is no difference in speech isolects within a society. There can be bilingualism and linguistic systems are expected to be based on the concept of use in the determination of isolated language systems. The growth in bilingualism and linguistic interference by following the displacement of phenomena is disaggregated by appearances which are aspects of the new approach to language study. How is the use of language in a country? As a foreign language like English, French, German, and Dutch are the languages of exile. Foreign language proficiency is taught in a university at a certain level does not compete with national language and regional languages (in a country).

How is the use of language in a country? As foreign languages like English, French, Germany, and Dutch are foreign languages. Foreign language proxies are taught that institutions at some 
level do not compete with national and regional languages (in a country). I.e. in a country where a Foreign Language (FL) is English, French and Germany don't compete with Dutch.

In its capacity as a foreign language functioning as a liaison language of a nation, the goal of developing a national language into a modern language is used as a tool for the development of modern science and technology for the internal development of nationality in a country, and is also used as an international relationship in the next sequence for development Ideology, politics, economic, socio-cultural, and national security defense (Language Center, 1977: 14). As Crystal (1992: 34) emphasizes that it is not a matter of language identity in ethnic and national relations, ethnic identity is more loyal to the group with the ancestors, but for that matter now is the use of traditional culture used in ethnic terms, particularly used in foreign languages (FL), national languages (NL), and local languages (LL).

Between language and the other languages influenced towards one another with complementary elements as what one acknowledged for their loans and borrowing of words. In the example of the words use of English loan from Arabic illustrated as follows:

The Loan of English Words from Arabic

\begin{tabular}{ccc}
\hline $\begin{array}{c}\text { Arabic } \\
\text { Language }\end{array}$ & English Language & $\begin{array}{c}\text { Contact of } \\
\text { Language }\end{array}$ \\
\hline Maryam & Maria & Loan \\
Daud & David & Loan \\
Ibrahim & Abraham & Loan \\
$\ldots$ & $\ldots$ & $\ldots$ \\
\hline
\end{tabular}

As a National Language (NL) The other seat as a NL, the function NL as the symbol of national pride, symbol of national identity, a mean unifying the various of people of different socio cultural background and language, communication tool intercultural and inter-regional. In his capacity as the state language, the function of NL as official state language, the official language of instruction in educational institutions, official language in communication at the national level for the benefit of planning and governance, and official language in cultural development and use of science and modern technology (Language Centre, 1977: 13).

So also there has been a loan from FL to NL as in the state Indonesian $<\mathbf{k i t a b}>$ Arabian 'book'; $<$ pensil> English 'potlot'; <sirsak> Portuguese 'soursop'; <toge> China '...'; < bengkel > Dutch 'workshop' ... . In Indonesian have not yet the concept laptop, key board, printer, and mouse in ICT (International Communication and Technology) to fill the void concept and then that words borrowed in to NL of State Indonesian like that one.

As a Local Language (LL) by Language Centre is set position as the symbol of regional pride, the symbol of regional identity, mean transposition of family and local community. In the other function related the NL serves as a regional language, the language of instruction in primary school in certain are i.e. mother tongue at the beginning level to facilities the teaching of $\mathrm{NL}$ and other subjects; development tool and supporting regional culture. To enrich NL, for example in Indonesia donation vernacular has accrued as loan or uptake word i.e. in regional of state NKRI (Negara Kesatuan Republik Indonesia 'The Unity State of Indonesian Republic') as in example word of <mantan> Palembang 'ex'; <senjang> Minangkabau 'gap'; <gambut > Sunda 'turf'; < (suku) cadang > Lampung 'parts' ... 
Based on the ecology of language described above, the language ecology environment involves language in the language and culture of native speakers, language contact has occurred which resulted in a strata of isolects language, namely isolects languages, dialects, and sub dialect. If the speakers used in accordance with the situation of users and use it will determine itself the prestige of native speakers the mirror of good language, when speaking in accordance with the rules of language and culture, it is considered a prestigious speaker is good and right, '... a large sample who spokes a language to other ... the reported result in this paper focuses on the importance of language prestige in language or dialect' (Clarissa Surek-Clark, 2000: 266)

\section{CONCLUSION OF STUDY}

The linguistic study of language ecology within the language environment is determined by the learners and practitioners of language isolects, this happens to be called the language contact. The use and contact of languages in a country at least confronting three dimensions, FL, NL, and LL in the archipelago or western Austronesian languages may also be in other countries also in formal, informal or non-formal situations in which the language contact has taken place.

On the basis of the language ecology described above, the ecological environment of the language includes the language and culture of native speakers, the contact language that has taken place that is generated within the rank of isolated languages undergoing a status change called language, dialect, and subdialec isolates. If the speaker uses the language according to the user's situation and its use will determine the speaker's prism as a good language mirror, when the speaker speaks according to the language and culture rules, this is considered the prestige of a good and proper speaker. "Much of what is spoken about other languages, has been presented in this paper focusing on the prestige of language (in speech) language or dialect" (Clarissa Surek-Clark, 2000). Likewise in the language status in the language or dialect environment the dialect has been used based on the user's situation and the use of good and correct, if appropriate formal rules of use are considered good and correct. The effectiveness of language usage based on the speaker's situation and its use is a reflection of the prestige of using good and proper language in a country.

\section{ACKNOWLEDGEMENT}

Further thanks to the rector of the University of Muhammadiyah Metro, Lampung Indonesia which was commissioned for the workshop of writing scientific papers held by Kopertis II Palembang. The same remark is also addressed to the Koordinator Kopertis II Palembang who has organized a workshop Writing Scientific article in Southern Sumatra. We also would like to express gratitude to the resource persons in the workshop, namely Siti Nurmaini, Erna Yuniarti, and Ardian Ulvan of Kopertis II Palembang October 12, 2016. Thanks to the journal publishers who have been willing to watch and post this article so as to be appropriate for publication as like. Similarly, do not forget I thank the colleagues who had shared at the writing of this article; hopefully good deeds of all parties are given a reward from Allah ... amen.

\section{Reference}

Center for Development and Language Development, (1977). Hasil Perumusan Seminar Politik Bahasa Nasional 2528 Februari 1975. Jakarta: Center for Development and Language Development Department of Education and Culture

Clarissa Surek-Clark, (2000). Dialect Acquisition and Prestige in U. Penn Working Papers in Linguistics, Volume 6.3. Philadelphia: Departement of Linguistics University of Pennsylvania

Crystal, David. (1992). The Cambridge Encyclopedia of LANGUAGE: Social Identity p. 42. USA-New York: Cambridge University Press

Edi Subroto, H.D. (1992). Introduction to Structural Linguistics Research Methodology. Surakarta: Surakarta University Press 
Falk, Julia S., (1978). Linguistics and Language: A Survey of Basic Concepts and Implications. New York: Publisher of John Wiley \& Sons

Fasold, Ralph, (1984). The Sociolinguistics of Society. Oxport: Basi Blackwell Ltd.

Haugen, Einer. (1966). American Anthropologies: Dialect, Language, Nation. Contribution the Seminar on Sociolinguistics at Indiana University. Publisher by Harvard University Press

Haugen, Einer. (1972). The Ecology of Language: Essay by Einar Haugen (Ed. Anwar S. Dil). Stanford: Stanford University Press.

Halim, Amran. (1979). Development of National Language. Jakarta: Center for Development and development of Language Department of Education and Culture

Heidet, Karl M. (1968): Modernization or Westernization, in The Modernization of Language in Asia, Sutan Takdir Alisjahbana (Ed.). The Malaysian Society of Asian Studies, Kuala Lumpur p.28

Hornby, A.S, (1995). Oxford Advanced Learner's Dictionary of Current English. New York: Oxford University Press

John Edwards, (1995). Multilingualism: Chapter 4 Languages in Conflict page-89. England: Publisher in Penguins Book

John Edwards, (2011). Language and Identity (Key Topics in Sociolinguistics). Cambridge: Cambridge University Press

Mahsun, (1995). Diachronic dialectology: An Introduction. Yogyakarta: Gadjah Mada University Press

Procter, Paul. (1982). Longman Dictionary of Contemporary English. Great Britain: The Pitman Press

Sudirman, AM. (2015). Indonesian Youth in Three Dimensions Language (Alternative Preparatory Youth National Competitiveness Indonesia) on page 95-107 in PROSIDING NOVEMBER, 152014 NATIONAL SEMINAR Muhammadiyah University Metro 2014: HIGHER EDUCATION WELCOME COMPETITIVELY ASEAN FREE MARKET, ISBN: 978-602-70106-8-0. Metro, Lampung, Indonesia: UM Metro Publisher Research Institute Press

Sudirman, AM. (2016). Development of Characters Themselves through Learning Indonesian Language and Literature on page 477 in Proceeding THE 1 $^{\text {st }}$ ICONLEE (The First International Conference on Law, Economics and Education) Muhammadiyah University of Metro, November 12-13 2016. ISBN 978-602-74135-3-5 Bandarlampung-Indonesia: Proceeding in Muhammadiyah University of Metro

Tarigan, Henry Guntur (2009). Prinsif-Prinsif Dasar Metode Penelitian Pengajaran dan Pembelajaran Bahasa: Bab IV Analisis Data Penelitian. Bandung Indonesia: Publish of Angkasa Press

Uriel Weinreich (1979). Languages in Contact. New York: Mouton Publisher

Vogt, Hans.(2016). Language Contact. http://www.tandfonline.com/action/journalinforma-tion? journal Code/rwrd20

Vredenbregt, Jacob (1985). Pengantar Metodologi untuk Ilmu-Ilmu Empiris. Jakarta: The Publish of PT Gramedia 